\title{
BİR ÖRGÜTSEL KÜLTÜR OLARAK PAZARLAMANIN KURAMSAL ÇERÇEVESI
}

Zübeyir ÇELIK ${ }^{1}$

$\ddot{O Z Z}$

Anahtar Kelimeler:

Pazarlama Düşüncesi, Pazar Yönelimi,

Örgütsel Kültür

JEL Kodlarl:

M30, M31
Received Date (Başvuru Tarihi): 23/01/2020

Accepted Date (Kabul Tarihi):27/02/2020

Published Date (Yayın Tarihi):25/04/2020

THEORETICAL FRAMEWORK OF MARKETING AS AN ORGANIZATIONAL

\section{CULTURE}

\section{ABSTRACT \\ Keywords: \\ Marketing Thinking, Market Orientation, Organizational Culture}

JEL Codes: M30, M31
Geçmişte olduğu gibi, pazar yönelimi, özellikle bir örgüt kültürü olarak firma uygulamaları için önemli bir kavramdır. Bununla birlikte, ilgili literatürde pazar yönelimi kavramı için genel kabul görmüs bir tanım yoktur. Bu nedenle, bu çalışmanın amacı, teorik çerçeve içerisinde bir örgüt kültürü olarak pazarlama kavramını açıklı̆̆a kavuşturmaktır. Bu amaç için, ilgili literatürdeki birincil ve ana kaynaklar özellikle referans kaynaklarıdır. Literatür incelemesine göre, pazarlama düşüncesinin temeli olan pazar yöneliminin felsefi temelleri 1950'lerin başına dayanmaktadır. Örgütler 1960'ların sonlarındaki rekabetçi baskılar nedeniyle bir pazar biçimi olarak popüler hale gelmişlerdir. Bununla birlikte, bir örgüt kültürü olarak pazarlama üzerine ilk çalışmaların 1980'lerde yazıldığını belirtmek ilginçtir, Ilgili bulgular, geçmişten günümüze tarihsel dönemler itibariyle çalışmanın sonucunda gösterilmiştir.

As in the past, market orientation is an important concept especially for firm practices as an organizational culture. However, there is no generally accepted definition for the concept of market orientation in the relevant literature. Therefore, the aim of this study is to clarify the concept of marketing as an organizational culture within the theoretical framework. For this aime, primary and main sources in the relevant literature are particularly reference sources. According to the literature review, the philosophical foundations of market orientation, which are the basis of marketing thinking, date back to the early 1950s. Organizations became popular as a form of market due to competitive pressures in the late 1960s. It is interesting to note, however, that the first studies on marketing as an organizational culture were written in the 1980s. Related findings are shown in the conclusion of the study as of historical periods from past to present.

\footnotetext{
${ }^{1}$ Arş. Gör., Van Yüzüncü Yll Ünv., Erciş İşletme Fakültesi, İşletme Bölümü. zubeyircelik@yyu.edu.tr, https://orcid.org/0000-0003-1692-9378
} 


\section{GíRiş̧}

Yirminci yüzyıl içinde zira 1900'lerin daha başında örgütlerin karşılaştı̆̆ en büyük zorluk malları ve giderek karmaşılaşan bir toplum için hizmetleri verimli bir şekilde üretmek olmuştur. 1960'lı yılların sonlarında karşılaşılan yeni rekabetçi güçlükler, pazar biçimi örgütlenmeleri popüler hale getirmiş̧tir (Cameron ve Quinn, 2006).

1980'li yılların başına gelindiğinde, akademisyenler, örgütsel olarak kültür kavramına ciddi bir ilgi göstermeye başlamışlardır. Bununla beraber, 1980'li yılların ikinci yarısında pazarlama kavramı, rekabet yoğunluğu ve örgütsel performans bağlamında ele alınmıştır (Bakınız, Lusch ve Laczniak, 1987). Bu bağlamda düşünüldüğünde pazarlama literatürü, 1980'li yılların başından beri ilkin örgütsel çalışmalar sahnesi üzerine patlak veren kültür perspektifine yönelik birçok ilginç aşamada gelişim göstermiştir (Denison, 1996). Bu yıllar itibari ile akademisyenlerin ve uygulamacıların ilgileri "pazar yönelimi” kavramına kaymıştır (Kohli vd., 1993). 1989 yılında pazar yönelimi üzerine ilk çalışmayı yapan Deshpande' ve Webster (1989) olmuştur.

Öte yandan, Narver ve Slater (1990) yapmış oldukları çalışma ile pazar yönelimi ve performans ilişkisi üzerine ilk adımı atmışlardır. Narver ve Slater'ın (1990) çalışmasının ardından 1990'ların ilk yarısında, Deshpande' vd. (1993) tarafından yapılmış olan çalışmayla birlikte pazar yöneliminin ölçülmesine, bu ölçümlerin firma performansıyla ilişkilendirilmesine yönelik kayda değer bir ilerleme olmuştur. Burada, pazar yönelimi karar verme bakış açılarından olan kültürel temelli davranışsal bakış açısı (Narver ve Slater, 1990) ve müşteri yönelimi bakış açısı (Deshpande' vd., 1993) konusu ilk kez ilgili çalışmalara konu olmuştur (Joseph ve Francis, 2015). Pazar yönelimi karar verme bakış açılarından biri olan pazar yönelimi bakış açısının en yüksek önceliği, üstün müşteri değerinin kârlı olarak inşa edilmesi ve sürdürülmesi üzerinedir (Narver ve Slater, 1990). Buna karşılık, pazar yönelimi karar verme bakış açılarından biri olan kültürel temelli davranışsal bakış açısı bağlamında düşünüldüğünde 1990'lı yıllarda örgüt kültürünün ve ilgili davranışların performans üzerindeki etkisini inceleyen giderek büyüyen bir literatür gelişim göstermiş̧ir (Deshpande' ve Farley, 1999). Bir kültür olarak pazarlama kültürü (Christensen, 1995), belirli kimliklerin ortaya çıarılması, pekiştirilmesi ve sürdürülmesi için özenle tasarlanmış ve düzenlenmiş imgeler ve işaretlerle doymuş bir kültürü temsil etmektedir. Böylece, günümüze doğru işletme ortamının veya kültürünün daha fazla artan çeşitlilik, bilgi ve beklenen hız ile karakterize edildiği görülmektedir. 
Öte yandan, pazar yönelimi kavramına yönelik Türkiye'de pek çok çalışma kaleme alınmıştır. Zira, pazar yönelimi kavramı, ders kitapları (Bakınız, Tek, 1997) ötesinde 1997 yılında hazırlanmış olan tez çalışmasına ilk kez konu olmuştur (Bakınız, Can, 1997). Ayrıca, pazar yönelimi kavramı, 2000'li yılların daha başında bir dizi tez çalışmasına da konu olmuştur (Bakınız, Atilla, 2000; Yenilmez, 2000a).

Nihayet, ilgili literatürde yer alan özellikle birincil ve temel referans kaynaklar bağlamında bu çalışmanın amacı, kuramsal çerçevede bir örgütsel kültür olarak pazarlama kavramına açıklık getirmektir. Bu konu ve amaç çerçevesinde bu çalışmada, ilkin pazar yöneliminin felsefi temeline ve örgütlerde bir kültür olarak pazar yönelimine açıklık getirilmiştir. Ardından çalışmanın bulguları bağlamında pazar yönelimin, kaynak temelli yaklaşım, ürün yaşam döngüsü, rekabetçi avantaj, örgüt performansı ve yenilikçilik ile olan ilişkisi ele alınmıştır. Aynı zamanda, bir paradigma kayması olarak pazar yöneliminden ilişki yönelimine olan dönüşümden bahsedilmiştir. Nihayet, çalışmanın sonuç kısmında 1950, 1960 1970,1980, 1990 ve 2000 yılları itibari ile altı dönemsel bağlamda çalışma bulgularına yönelik özet bir çerçeve sunulmuştur.

\section{PAZAR YÖNELİMİNIN FELSEFÎ TEMELİ}

1950'lerin başlarında tanıtılan pazarlama kavramının ya da başka bir ifadeyle pazar yöneliminin felsefi temeli, pazarlama düşüncesinin temelini temsil etmektedir (Jaworski ve Kohli, 1993). Buna göre, pazarlama yönelimi, geçmişin ardından büyüyen pazarlarda kârlı ilerlemenin temel bir unsuru olarak kabul görmüştür.

1950’li yıllara müteakip 1960'lı yıllar, pazarlamanın etkisinin en büyük olduğu ve nüfuzunun çok baskın görüldüğü dönemdir (Day ve Wensley, 1983). Sonuç olarak, pazar yönelimi fikri, bir pazarlama kavramı içinde bir değerlendirme görmüştür. Bu bağlamda pazarlama kavramı, 1950'li ve 1960'lı yıllardaki eklem ve gelişiminden beri pazarlamanın bir köşesi, önem arz eden bir konusu olmuştur.

Pazarlama kavramına göre, firmanın tüm alanlarının müşteri yönlü olması gerekmektedir. Öyle ki, pazarlama kavramının tanımı, müşteri odaklı olarak kabul edilen firmanın tüm faaliyet alanlarına, tüm pazarlama faaliyetlerinin entegre edilmesine ve hem satış hem de kâr amacına yöneliktir (Hunt ve Morgan, 1995).

Diğer taraftan, pazar yönelimi üzerine ilk çalışma Deshpandé ve Webster (1989) tarafından yapılmıştır. Bu çalışma, bir firma kültürünün parçası olan değerler ve pazarlama 
kavramını uygulayan faaliyetler şeklinde pazar yöneliminin iki yorumuna yol açmıştır (Gainer ve Padanyi, 2005). Özellikle bir işletmenin rekabet avantajı stratejisinin temelini teşkil eden pazar yönelimli bir kültür, müşteri yönelimi, rakiplere odaklanma ve işlevler arasındaki koordinasyon şeklinde üç ana davranıştan meydana gelmektedir (Narver ve Slater, 1990). Keza, pazar yönelimi, bir davranış türü olan müşteri yönelimi ve örgütün iş performansını iyileştirmek için uzun vadeli kararlarına yönelik rakip yönelimi ile ilgilidir (Gatignon ve Xuereb, 1997). Dahası, pazar yönelimi, emtia üreten işletmelerin ve ticari olmayan işletmelerin faaliyetleri üzerinde önemli bir olumlu etkisi olmaktadır. Ancak, yaygın olarak kabul edilen bu öneme rağmen, pazar yönelimi konusunu dar çerçevede işleyen bir dizi kavramsal makale ve birkaç ampirik çalışma vardır (Jaworski ve Kohli, 1993). Bununla birlikte, akademisyen ve uygulayıcıların ilgisinin daha geniş bir çerçevede pazar yönelimi konusuna kayması mümkün görünmektedir (Jaworski ve Kohli, 1993). Zira, pazarlama kavramı, en uygun pazarlama yönetim felsefesi olarak akademisyen ve uygulayıcılar arasında sağlam bir şekilde kabul görmeye devam etmektedir (Turner, 1997).

\section{3. ÖRGÜTLERDE BİR KÜLTÜR OLARAK PAZAR YÖNELIMİ}

Kültür, nasıl ekonomik olabilir? Bu soruya cevap için Camerer ve Vepsalainen (1988) tarafından bir çalışma yayımlanmıştır. Bu çalışmaya göre, kurum kültürü teorilerin çoğu, toplumsal kültür hakkında antropolojik düşünceyi barındırmaktadır. Firma ve çalışanlar arasındaki kurallara yönelik firmaların etkinlik motivasyonları, kültürün nasıl ekonomik olabileceğini açıklamaktadır. Örneğin, işlemlerin maliyetine ve örgütsel yapıya yönelik etkinlik temelli bir teorinin, birçok test edilebilir etki oluşturması ve yöneticilerin, bir kültürü nasıl oluşturabileceklerine ve yönetebileceklerine yönelik bazı normatif etkiler yapması mümkün görünmektedir.

Diğer taraftan, 1990 yılların başında kültür tanımlarını ve pazarlama kavramını bütünleştirerek, pazarlama kavramını kültür olarak ele alan Kohli ve Jaworski’ye göre (1990), bu perspektifi benimseyen bir kuruluşun müşterilerin mevcut ve gelecekteki ihtiyaçlarını ve bunları etkileyen faktörleri anlamaya yönelik faaliyetlerde bulunan bir veya daha fazla departmana sahip olması gereklidir. Aynı zamanda, bu perspektif anlayışının, departmanlar arasında paylaşılması ve belirli müşteri ihtiyaçlarını karşılamak için tasarlanan, faaliyetlerde bulunan çeşitli departmanların olması gerekmektedir (Turner, 1997). Örneğin, sosyal bir kurum olarak pazarlama yönetimi tarafından “strateji, pazar yönelimli” bir örgütlenme etiketi altında hem örgütsel tasarım olarak tanımlanan kimliğin hem de pazarın ihtiyaç ve isteklerine yönelik 
olarak esnekliğin tanımlanması ve bu ikisinin uyum içinde yönetilmesi gerekmektedir (Christensen, 1995).

Buna karş1lık, 1992 yılında Webster (1992), müşteriye yönelen örgüt kültürünü, ağ örgütünün tekliğini tanımlayan ve çeşitli görevlerini ortak misyon ve hedeflere doğru koordine eden önemli bir stratejik kaynak olduğunu belirtirken müşteri yöneliminin, bilgi ve bilişim teknolojisine giderek daha fazla yatırım yapılmasına sebebiyet verdiğini ve bu alanlarda önleyici yatırımlar yapacak kadar büyük firmalara avantaj sağlayabildiğinden işletmedeki herkesin, iş tanımının ve örgüt kültürünün bir parçası olması gerektiğini belirtmiştir. Bununla beraber Anderson (1982), müşteri tabanlı bir perspektiften bakıldığında, pazarlamanın stratejik planlamadaki rolünün üç ana faaliyete indirgenebileceğini belirtmektedir. İlki hem kurumsal hem de bölümsel seviyelerde müşteri memnuniyet ve desteğini sağlayacak en uygun uzun vadeli pozisyonu veya pozisyonları tanımlamadır. İkincisi, pazarlamanın ikinci büyük stratejik planlama faaliyeti, tercih edilen pozisyonları yakalamak için tasarlanan stratejilerin geliştirilmesini içermedir. Son olarak üçüncüsü, pazarlama stratejilerini uygulamak için üst yönetim ve diğer fonksiyonel alanlar ile müzakere etmedir.

\section{YÖNTEM}

\subsection{Amaç}

İlgili literatürde akademisyenler arasında pazar yönelimi kavramı için genel kabul gören net bir tanımın olmadığı görülmektedir. Bu bağlamda bu çalışmanın amacı, kuramsal çerçevede bir örgütsel kültür olarak pazarlama kavramına açıklık getirmektir.

\subsection{Prosedür}

$\mathrm{Bu}$ çalışma amacına yönelik, ilgili literatürdeki birincil ve ana kaynaklar özellikle referans kaynaklarıdır. Bu kaynaklar çerçevesinde ilgili literatür incelemesi yapılmıştır.

\subsection{Veritabanı ve Kısıtlar}

Çalışmanın amacı bağlamında bu çalışmanın veritabanı, dergi makaleleri, ders kitapları ve hazırlanmış olan tezlerdir. Google scholar ve YÖK Tez Merkezi veritabanı üzerinden referans çalışmalara ulaşmak için Türkçe pazar yönelimi, pazar yönlülük, pazar oryantasyonu, pazara dönüklük, örgüt kültürü, şirket kültürü, firma kültürü ve İngilizce market orientation, organizational culture, corporate culture ve firm culture anahtar kelime kısıtları altında taramalar yapılmıştır. Böylece, 1950 yılı itibari ile yayımlanan bir dizi çalışmaya ulaşılmış ve bu çalışmalar bağlamında literatür gözden geçirilmiştir. 


\section{BULGULAR}

Bir örgütsel kültür olarak pazar yönelimi kaynak temelli yaklaşım, ürün yaşam döngüsü, rekabetçi avantaj, örgüt performansı ve yenilikçilik ile olan ilişkisi vardır. Yani bir örgütsel kültür olarak pazar yönelimi kavramı için kaynak temelli yaklaşım, ürün yaşam döngüsü, rekabetçi avantaj, örgüt performansı ve yenilikçilik örgütsel kültür olguları bağlamında genel kabul gören bir tanım yapmak mümkündür.

Bununla birlikte, pazar yöneliminden ilişki yönelimine yönelik bir paradigma kayması söz konusudur. Zira, ilişkisel pazarlamaya duyulan gereksinimden ötürü bir örgütsel kültür olarak ilişki yönelim konusunu işlemiş çalışmalar vardır. Çalışma bulguları aşağıdaki sayfalarda ilgili başlıklar altında detaylı şekilde ele alınmıştır.

\subsection{Pazar Yönelimi ve Kaynak Temelli Yaklaşım}

Lipmann ve Rumelt (1982) kaynak temelli yaklaşımın öncülerindendir. Bununla birlikte, kaynak temelli yaklaşım, Penrose (1959), Richardson (1972) ve Teece (1980) gibi tarafındaki başlıca çalışmalarda görüleceği üzere iktisat bilgisine dayanmaktadır. Yani, kaynak temelli yaklaşım, genelde iktisat literatüründe önemli katkılarda bulunan ve bazı konulara yönelik katkı yapmaya devam eden bireysel araştırmacılar tarafından geliştirilmiştir. Öyle ki, işlem maliyetleri ekonomisi ve pozitif ajans teorisi, kaynak temelli yaklaşımla doğrudan ilgilidir (Lockett ve Thompson, 2001).

Kaynak temelli yaklaşımın savunucularından olan Barney’e (1991) göre, sürekli rekabet avantajının, değerlilik, nadirlik, taklit edilebilirlik ve ikame edilebilirlik olarak dört temel kaynağı vardır. Bununla beraber, Collis’e göre (1994), örgütsel becerilere yönelik sürdürülebilir bir rekabet avantajı kaynağının değeri, firmanın içinde bulunduğu koşullara bağlı olarak farklılık göstermektedir. Aynı zamanda, farklı sektörlere göre farklı nokta ve yerlerde bulunabilen sürdürülebilir kaynakların örgütsel becerilere yönelik önem dereceleri benzer değildir. Öte yandan, 1991 yılında Barney (1991) tarafından yayımlanan çalışmanın ardından yaklaşık on yıl sonra kaynak temelli görüş, stratejik yönetim ve ilgili disiplinlerde hem heyecan duygusunu uyandırmış hem de tartışmayı beraberinde getirmiştir (Barney vd., 2001). Zira, kaynak temelli yaklaşımına yönelik strateji ve ekonomi disiplinleri arasında açık olan ancak farklı bakış açılarını barındıran bir ilgi söz konusudur (Lockett ve Thompson, 2001). Bununla birlikte, 1991 ve 2001 yılları arasında hem pazarlama teorisyenlerinin (Hunt, 2000) hem de kaynak temelli yaklaşım savunucularının (Barney, 1991) örgütlerin varlığını sürdürmeleri için rekabette üstünlük 
kazandıran nedir ve rekabet üstünlüğü nasıl sürdürülebilir şeklinde en temel soruya cevap aradıkları görülmektedir (Srivastava vd., 2001).

Pazar güdümlü örgütlerin en ayırt edici özellikleri, pazarı algılamaları ve müşteri bağlantı yeteneklerine hâkim olmalarıdır (Day, 1994). Burada, müşteri bağlantı yetenekleri, geliştirmeyi amaçlayan kapsamlı bir değişim programının mevcut kabiliyetlerin teşhisi, yetenekler için gelecekteki ihtiyaçların öngörülmesi, altta yatan süreçlerin aşağıdan yukarıya yenilenmesine, yukarıdan aşağıya yönlendirme ve bağlılığa, bilgi teknolojisinin yapıcı kullanımına ve ilerlemenin sürekli izlenmesine yöneliktir (Day, 1994). Diğer taraftan, pazarlama teorisi ve pratiğinin geleceği için örgütsel olarak gömülü bir pazarlama görüşünün etkilerine vurgu yapılması gerekmektedir. Zira, belirli bir çerçevede, pazarlamanın iş süreçleri ve paydaş değeri ile bütünleşmesini anlamak için pazarlama olguları yeniden ele alınmalıdır. Pazarlama olgularını, paydaş değerini meydan getiren üç temel iş sürecine sırasıyla ürün geliştirme yönetimine, tedarik zinciri yönetimine ve müşteri ilişkileri yönetimine gömülü olarak yeniden tanımlamak mümkündür (Srivastava vd., 1999).

Nihayetinde, kaynak temelli yaklaşım ve pazarlama bağlamı konusundaki ilgiler göz önüne alındığında, Day (1994) ve Srivastava vd. (1999) ardından, ürün geliştirme ya da ürün geliştirme çözümleri, ürün geliştirme yönetimi, tedarik zinciri yönetimi ve müşteri ilişkileri yönetimi konularına odaklanan pazar yönelimli ya da temel işletim süreçleri ile insan kaynaklarının edinimi, geliştirilmesi ve dağıtımı gibi müşteri yönelimli olmayan süreçler arasında ilgili çalışmalarda ayrım yapıldığı görülecektir. Örneğin, Srivastava vd. (2001) kaynak temelli yaklaşımın, pazarlama ile olan ilişkisini ele almak için pazar temelli kaynakların analiz çerçevesini çizmişler ve pazarlamaya özgü kaynakları Şekil 1'de olduğu gibi göstermişlerdir. 


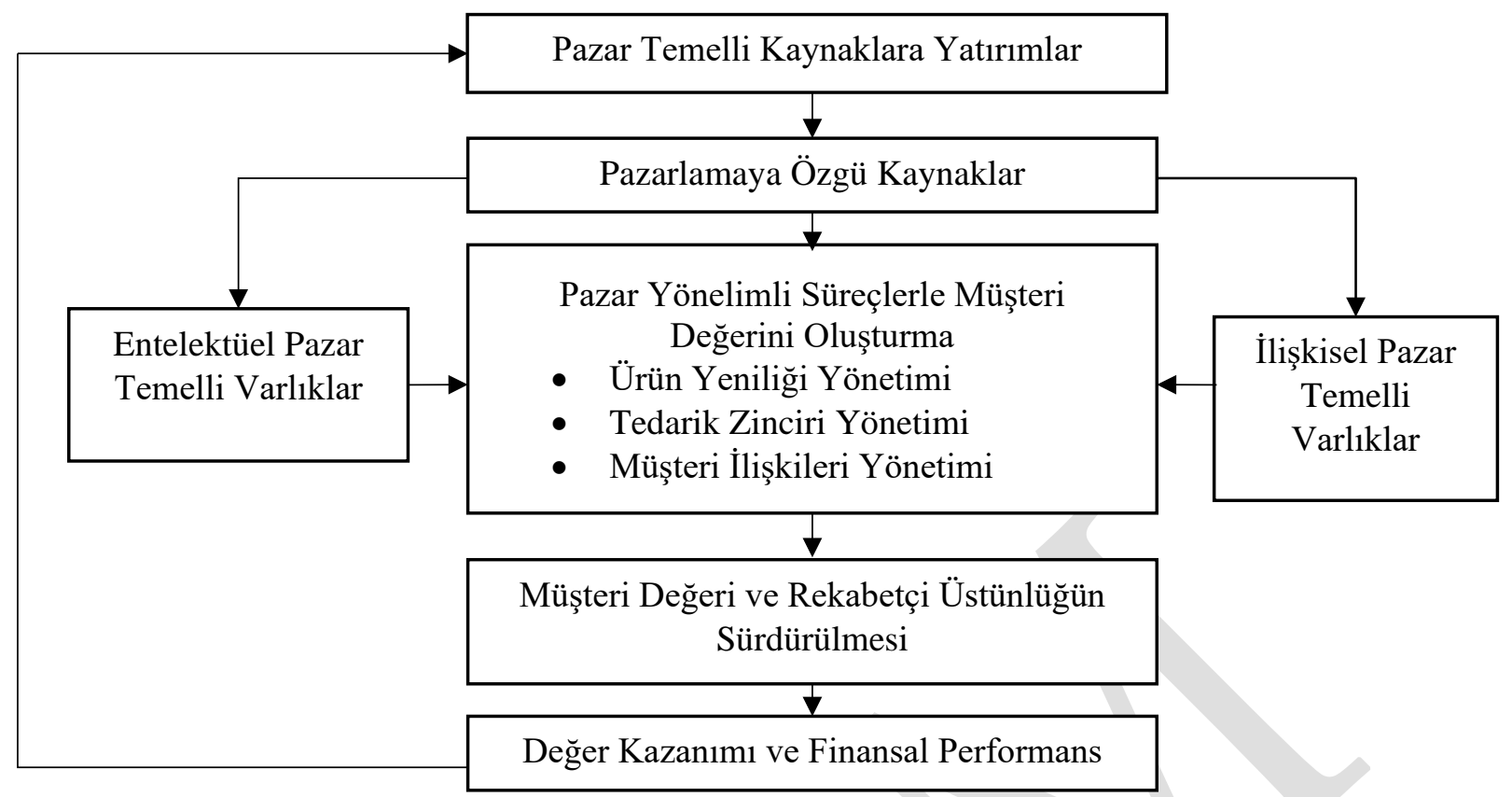

Şekil 1. Pazar Temelli Kaynakların Analizi İçin Çerçeve

Kaynak: Srivastava vd. (2001)

Nihayet, 1960'lardan 1980'lerin sonuna kadar stratejide kaynak temelli yaklaşım konusu, dışsal yani ürün pazarı rekabet avantajı kaynaklarının dikkate alınmasıyla dikkat çekmiştir (Lockett ve Thompson, 2001). Dolayısıyla bu çerçevede düşünüldüğünde öncellikle pazar yönelimi ve rekabetçi avantaj arasındaki ilişkiye değinilmeden önce pazar yönelimi ve ürün yaşam döngüsü arasındaki ilişkiye açıklık getirmek daha doğru ve yerinde olacaktır.

\subsection{Pazar Yönelimi ve Ürün Yaşam Döngüsü}

Ürün yaşam döngüsü Dean (1950) tarafından pazarlama literatürüne tanıtılmıştır. Pazarlama literatürüne tanıtılan ürün yaşam döngüsü, pazar dinamiklerini tanımlamak ve açıklamak için yararlı olan ve iyi bilinen mecazi bir kavramdır (Day, 1981). Ürün yaşam döngüsünün özü, ürün pazarlarının benzersiz talep ve rekabet koşullarına göre ayırt edilebilen giriş, büyüme, olgunluk ve düşüş şeklinde dört ayrı ve geçici aşamadaki gelişmesine göredir (Wong ve Ellis, 2007). Buna karşılık, ürün yaşam döngüsünün bu evreleri kapsamında, müşteri ihtiyaç ve beklentileri sürekli olarak ancak zamanla gelişime tabi olmaktadır. Dolayısıyla hem mevcut pazarın hem de değişen pazarın ihtiyaçlarına yönelik sürekli yüksek kaliteli ürünler ve hizmet sunumları için sürekli izlemeler yapılmalı ve buna göre tepkide bulunulmalıdır. Öyle ki, son y1llarda, mevcut müşterilere üstün kaliteli ürün ve hizmet sunmaya yönelik yeni bir vurgu yapılmaktadır (Jaworski ve Kohli, 1993). 
Bununla birlikte, pazar yönelimi ve iş performansı arasındaki ilişkiye yeterince bilimsel ilgi gösterilmediğinden, ürün yaşam döngüsünün pazar yönelimi üzerindeki etkisi konusuna yönelik sınırlı sayıda çalışma mevcuttur (Wong ve Ellis, 2007). Pazar yönelimi ile firma performansı arasındaki bağlantı, büyüme aşamasındaki firmalar için en güçlü olmasına karşılık ürün yaşam döngüsünün giriş aşamasındaki firmalar için en zayıftır (Wong ve Ellis, 2007). Diğer taraftan, ürün yaşam döngüsünün belirli aşamaları ile sınırlı kalmayan pazar rekabeti ve endüstri arasındaki muhalefetin, çatışmanın algılanan şiddeti yüksektir. Bu bakımdan, ürün yaşam döngüsünün daha ilk aşamasında pazar yöneliminin etkisi daha fazla önem arz etmektedir. Zira, pazar rekabeti ve endüstri arasındaki tipik çatışma, ürün yaşam döngüsü ilerlemesine bağlı olarak genellikle yoğunlaşmakta ve böylece pazar yöneliminin etkileri daha çok kendini göstermektedir (Atuahene-Gima, 1995).

Sonuç olarak, son yirmi yılda sanayi yapısında ve küresel bağlantıda hızlı değişiklikler meydana gelmesi itibari ile geleceğin çevresinin veya ortamının, daha fazla artan çeşitlilik, bilgi ve beklenen hız ile karakterize edilmesi mümkün görünmektedir (Achrol, 1991). Bundan ötürü, bir firmanın diğer bir rakip firma ürünlerinin, fiyatlarının ve stratejilerinin, örneğin bir pazar yöneliminin uygulanmasından elde edilen bilgileri bazı pazar segmentlerindeki rakiplerine göre daha verimli veya etkili bir pazar sunma potansiyeline sahip olması önemle zorunluluk arz etmektedir (Glazer, 1991). Ayrıca, güçlü bir teknolojik yönelime ve yüksek büyüme pazarlarında rekabetçi bir yönelime sahip olan bu firmanın, talebin nispeten belirsiz olduğu pazarlarda da tüketici ve teknoloji yönelimli olması gerekmektedir (Gatignon ve Xuereb, 1997). Nihayetinde pazar yönelimi ve performans arasındaki bağlantının, değișen pazar türbülansı, rekabet yoğunluğu ve teknolojik türbülans ile karakterize edilen çevresel bağlamlarda sağlam bir çerçeve çizdiği görülmektedir (Jaworiski ve Kohli, 1993).

\subsection{Pazar Yönelimi ve Rekabetçi Avantaj}

Özellikle 1990’lı yıllar içinde, akademisyen ve uygulamacıların ilgisinin pazar yönelimi kavramına kaydığı görülecektir (Kohli vd., 1993). Zira, 1990 yıllardan bu yana, pazar yönelimini inşa etmeyi konu edip araştıran giderek büyüyen bir araştırma akışı olmuştur (Homburg ve Pflesser, 2000). Bununla birlikte, yeni rekabet güçlükleriyle karşılaşılmasından ötürü 1960'ların sonlarında örgütlenmenin bir başka biçimi pazarların, popüler hale gelmiş olduğu görülecektir (Cameron ve Quinn, 2006). Dolayısıyla tam bu bağlamda rekabetçi avantaj teorisinin ne olduğunu açıklamak gerekir. Rekabetçi avantaj teorisinin açıklanmasında Anderson (1982), neoklasik model, pazar değer modeli ve ajans maliyeti şeklinde firma ile ilgili üç teoriyi ve öte 
yandan en iyi ekonomik teorinin neo-klasik modeline karşı bir tepki olabileceğini ifade eden firmanın davranışsal model yaklaşımını ve Pfeffer ve Salancik'in (1978) kaynak bağımlılık model yaklaşımını gözden geçirmektedir. Anderson'a (1982) göre, neo-klasik model, çağdaş mikro ekonomik teorinin temelini sağlamlaştırmakta; pazar değer modelin finansal ekonomi içinde benzer bir işlevi yerine getirmektedir. Diğer taraftan, insan isteklerinin doyumsuz ve sermaye piyasalarının tam olarak rekabetçi olması muhtemeldir. Dolayısıyla bu varsayımlar altında düşünüldüğünde pazar değer modeline göre firma, hedefe yönelik mevcut piyasa değerini maksimize etmelidir. Dahası, Anderson'a (1982) göre, ajans maliyet modeli bağlamında düşünüldügünde firma, sahip ve yöneticileri arasında bir çıkar ayrılığı sağlamak için pazar değer modelinde bir değişikliği temsil etmelidir. Sonuç olarak her üç model, ekonomik teori olarak metodolojik yönelimi ve kavramsal çerçeveyi paylaştıkları için ekonomik modeller olarak sinıflandırılabilmektedir (Anderson,1982). Çünkü her model, firma için ekonomik bir hedef oluşturmasının ardından farklı varsayım kümeleri altında firma davranışları için sonuçlar ortaya çıkarmaktadır (Anderson,1982). Öte yandan, Anderson (1982) tarafındaki çalışmada belirtildiği üzere, firmanın davranış teorisi yaklaşımını, Simon (1955, 1959, 1964), March ve Simon (1958) yazılarında ve özellikle de Cyert ve March (1963) yazısında bulmak olasıdır. Davranış teorisine göre işletme, bir şirket olarak alt-üst düzey üyeleri olan bireylerin bir koalisyondur (Anderson,1982). Çünkü, Pfeffer ve Salancik’in (1978) kaynak bağımlılık modeli yaklaşımı için örgütler, koalisyon yapısında meydana gelen değişiklikler olarak amaçlarını ve yönlerini değiştiren çıkar koalisyonlarıdır (Anderson,1982).

Bununla birlikte, Anderson'un (1982) firmanın bir iş teorisi olarak neo-klasik teoriyi ele almasına karşılık neoklasik mükemmel rekabet teorisine dikkat çeken Hunt ve Morgan (1995), rekabet avantajını incelemek için firmanın rekabet avantajını ve yetkinliklerini temel alan, rekabetçi ya da kaynak avantajlı teoriyi önermişlerdir (Bakınız, Şekil 2). Bu teori modeline göre pazar temelli ekonomilerde verimli ve etkili karşılaştırmalı kaynak avantajlarına sahip firmaların, zaman içinde rekabetçi pazar avantajlarına sahip olabilmelerine bağlı olarak çeşitli üstün çıktılar elde etmeleri olasıdır.

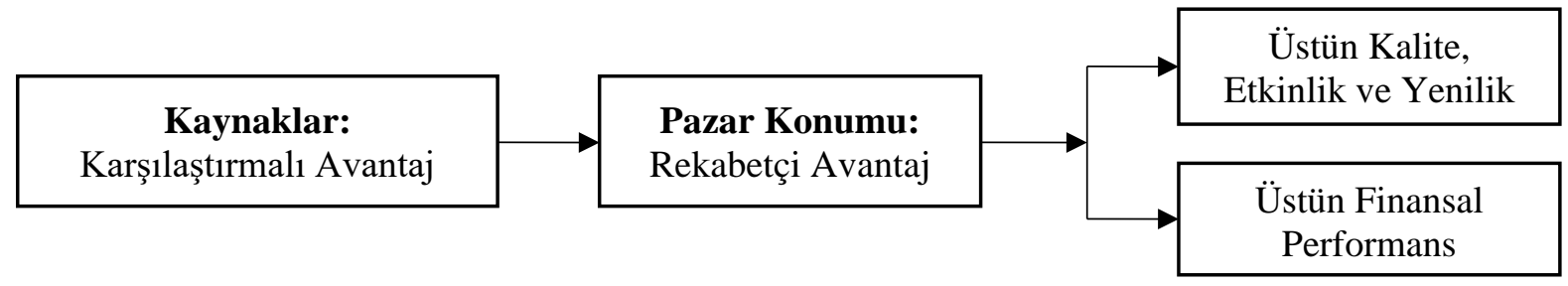

Şekil 2. Karşılaştırmalı Avantaj Rekabet Teorisi

Kaynak: Hunt ve Morgan (1995) 
Bununla beraber pazar yönelimini bir kaynak olarak gören Hunt ve Morgan’a (1995) göre, pazarlama kavramının müşterilere odaklanmasına karşılık, pazar yöneliminde hem müşteriler hem de rakiplere odaklanma vardır. Ayrıca, yeni rakipler ile sonuçlanan değişen teknolojinin tehlikelerine karşı korunmak için potansiyel rakipler görüldüğünden bir kaynak olarak pazar yönelimi, strateji oluşturmada hem müşteriler hem de rakipler hakkında bilgi kullanmanın önemine vurgu yapmaktadır. Nitekim, ticari markaları ve marka ederini (brand equity) birer kaynak olarak ele almak mümkündür. Dolayısıyla, pazarlama faaliyetleri rekabete aykırı olduğu muhtemel hallerde hangi kaynakların karşılaştırmalı olarak pazarlanabileceği ve hangi kaynakların karşılaştırmalı bir avantaj sağladığı sorusu önem arz etmektedir. Bu soruya yönelik olarak da son zamanlarda pazar yönelimi ve ortaya çıkardığı tartışmalar göz önüne alındığında, pazar yönelimini potansiyel bir kaynak olarak ele almak mümkündür. Dolayısıyla bunu yaparken, karşılaştırmalı üstünlük teorisini daha açık bir şekilde açıklayan Hunt ve Morgan (1995) teorinin nasıl konumlandırılması gerektiğini göstermişlerdir ve teorilerindeki kaynak avantajının rolüne vurgu yapmışlardır.

\subsection{Pazar Yönelimi ve Örgüt Performansı}

İş performansını iyileştirmek için sıklıkla pazar yönlendirmesinin yapıldığı görülebilmektedir (Jaworiski ve Kohli, 1993). Nitekim, pazar yönelimi, müşteri ve dağıtım kanalı bayilerinin gelişmesine, kârlılığın artmasına yol açmakta ve işletme performansı ile olan ilişkinin kurulmasına etki etmektedir (Knowles ve Ambler, 2009).

Bununla beraber, 1990 yılında ilk kez pazar yönelimi ve örgütsel performans arasındaki ilişkiye açıklık getirilmiştir. Zira, Narver ve Slater (1990) tarafından yapıllmış olan çalışma ile pazar yönelimi kavramı ve gelişmiş iş performansı bağlamında müşteri, uzun vadeli ve kapsamlı perspektif olarak üç farklı perspektifin ilk defa tanımı yapılmıştır (Knowles ve Ambler, 2009). Bu çalışmayla birlikte 1990 ve 1995 yılları arasında pazar yönelimi ve pazar yöneliminin firma performansıyla olan ilişkinin ölçülmesine yönelik ilgili literatürde kayda değer bir araştırma konusu olmuştur (Deshpande' ve Farley, 2004). Keza, örgüt kültürünün ve ilgili davranışların performans üzerindeki etkisini inceleyen giderek büyüyen bir literatür gelişim göstermiştir (Leisen vd., 2002). Nitekim konu ile ilgili çalışmalar çerçevesinde pazar yönelimi derecesi, büyük ölçekli kuruluşlar içindeki iş birimleri arasında değişmekte ve geniş örgütsel süreçlerle, kendi işlerine yönelik bireysel tutumlarla ve iş birimi uzun vadeli performansıyla olumlu ilişkili olmaktadır (Bakınız, Ruekert, 1992). Dahası, müşteri yönelimli kültür, müşteri yönelimli davranışlar ve örgütsel performans arasındaki olumlu ilişkiye aracılık etmekte ve ayrıca hem 
müşteri yönelimli kültür hem de müşteri yönelimli davranışlar, örgütsel performansı üzerinde etkili olmaktadır (Bakını, Gainer ve Padanyi, 2005). Son olarak belirtmek gerekirse aynı zamanda pazar yönelimi, stratejik insan kaynakları yönetimi ve örgütsel performans arasındaki ilişkiye aracılık etmektedir (Harris ve Ogbonna, 2001).

Bunun yanı sıra, 1997'li yıllar itibari ile Türkiye’de pazar yönelimi ve işletme performansı arasındaki ilişki konusuna yönelik yapılmış olan çalışmaların olduğu görülmektedir (Örneğin, Can, 1997; Atilla, 2000; Yenilmez, 2000b; Akman, 2003; Hatiboğlu-Yalman, 2003; Uzkurt, 2003; Danişman ve Erkocaoğlan, 2008; Bulut vd., 2009; Usta, 2011; Eris ve Ozmen, 2012; Keskin vd., 2016). Yapılmış olan bu çalışamalarda da görüleceği üzere pazar yönelimi ve örgütsel genel performans arasında olumlu anlamlı bir ilişkinin olduğu açıkçtır.

\subsection{Pazar Yönelimi ve Yenilikçilik}

Pazar yönelimini çeşitli yönlerde ele alan çalışmaların olduğu görülmektedir. Zira, 1990’l1 y1lların sonunda Hurley ve Hult (1998) tarafından pazar yönelimi, yenilikçilik ve örgütsel öğrenme temellinde ele alınmıştır. Yapılmış olan çalışma sonucuna göre, öğrenme, gelişme ve katılımcı karar verme kültür türleri, firma kültürüne yönelik yenilikçilik düzeylerine olumlu etki etmektedir. Dolayısıyla, yenilikçilik ile ilgili kültürel yapıların, pazar yönelimi ve örgütsel öğrenme ile ilişkilendirilmesi gerekmektedir. Bu bağlamda örneğin, Raj ve Srivastava (2016) tarafından yapılmış olan çalışma sonucuna göre, pazarlar, rakipler, endüstriler, müşteriler ve diğer paydaşlar hakkındaki bilgi, örgütsel öğrenme süreçleri aracılığıyla kullanılmaktadır. Buna karş1lık pazar yöneliminin, örgütsel öğrenme ile örgütsel yenilikçilik üzerinde olumlu etkileri olmaktadır. Bu çalışmanın yanı sıra, Zhou vd. (2005) tarafından yapılmış olan çalışmada pazar, teknoloji ve girişimcilik şeklinde üç önemli stratejik yönelim türü üzerinde durulmuştur. Zira, Zhou vd. (2005) tarafından yapılmış olan çalışma sonucuna göre, pazar yönelimi, ileri teknoloji kullanan ve ana müşterilere daha fazla fayda sağlayan yani teknolojiye dayalı yenilikleri kolaylaştırmaktadır. Ancak pazar yönelimi, gelişmekte olan pazar segmentlerini yani pazara dayalı yenilikleri hedefleyen yenilikleri engellemektedir. Diğer taraftan teknoloji yönelimi, teknolojiye dayalı yenilikler için faydalı olmaktadır ancak teknoloji yönelimin, pazara dayalı yenilikler üzerinde hiçbir etkisi yoktur. Girişimcilik yönelimi ise, her iki türdeki yani teknoloji ve pazar temelli yeniliklerde çığır açmayı kolaylaştırmaktadır.

Bununla beraber, O’Cass ve Viet Ngo (2007) tarafından yapılmış olan çalışma sonucuna göre, güçlü bir yenilikçi kültüre sahip örgütler için başarılı bir marka oluşturma her zaman mevcut müşterilerin ve rakiplerin geri bildirimlerinin yorumlanmasına bağlı değildir. Bunun 
yerine başarılı bir marka oluşturma, kuruluşların müşterilere üstün bir değer sunmanın benzersiz yollarını yenilikçi olarak geliştirebilme yeteneklerine bağlıdır. Buna karşılık, pazar yönelimi, kısmen kuruluşun yenilikçi kültüründen türetilen bir tepkiye karşılık gelmektedir. Son olarak, Eskiler vd. (2011) tarafından yapılmış olan çalışma sonucuna göre, bilgi yönetimi, pazar yönelimi ve pazarlama yeniliği olguları arasında ilişki vardır. Zira, pazar yönelimi ve pazarlama yeniliği arasında olumlu anlamlı bir ilişki söz konusu olmasına rağmen, bilgi yönetimi ve pazarlama yeniliği arasında olumsuz anlamlı bir ilişki söz konusudur. Bununla birlikte, pazar yönelimi ve bilgi yönetimi birlikte pazarlama yeniliği üzerinde olumlu bir etkiye sahiptir.

Öte yandan, firma performansını pazar yönelimi ile yenilikler etkisinde inceleyen çalışmaların olduğu görülebilmektedir. Örneğin, Farley vd. (2008) tarafindan yapılmış olan çalışma sonucuna göre, gelişmiş ve gelişmekte olan ülkelerde pazar yönelimi ve pazar yenilikçiliği, firma performansına ilişkin önemli faktörlerdir. Diğer taraftan Jogaratnam (2017) tarafından yapılmış olan çalışma sonucuna göre, destekleyici ve yenilikçi kültürel türlerin firma performansı üzerinde doğrudan etkileri olmakta ve pazar yönelimi, yenilikçi örgüt kültürünün firma performansına olan doğrudan olumlu etkisine aracılık etmektedir.

\section{6. Örgütlerde Bir Kültür Olarak İlişki Yönelimi}

Geçen yılların ardından hem pazarlama teorisi hem de uygulanmasında büyük bir yön değişikliği başlangıcına tanık olunmuştur. İlişkisel pazarlamaya duyulan gereksinim, küresel pazarın değişen dinamiklerinden ve rekabetçi başarı için değişen ihtiyaçlardan kaynaklanmıştır. Böylece, ilgili çalışmalarla pazar yöneliminden ilişki yönelimine doğru bir paradigma kayması olmuştur (Morgan ve Hunt, 1994).

Morgan ve Hunt (1994), bağl1lık ve güven teorisini özellikle, pazarlama ilişkilerinde ve ilişkisel pazarlamada ilk kez ortaya koymuşlardır. Özellikle bu teorinin ortaya konulmasının ardından yıllarla birlikte bir konu olarak 'ilişki' kavramı ilgili çalışmalarla çokça ele alınmaya başlanmıştır. Bununla beraber altını çizmek gerekirse, ilgili literatürde çoğu çalışmada görüleceği üzere ilişkisel pazarlamanın felsefesi ve teorik temellerinden bazısı, endüstriyel pazarlarda şebeke veya ağ yaklaşımındadır (Bakınız, Erdoğan vd., 2011). Nitekim, ilişsisel pazarlamanın ortaya çıkış nedenlerinin tartışıldığı mevcut çalışmaya (Bakınız, Sheth ve Sharma,1997) göre, etkin pazarlama stratejilerinde ilişkilerin çok önemli olduğuna dair kanıtlar mevcuttur ve örgütsel satın alma işlemi, ilişki yönlü düşünceye kaymıştır. Böylece, o yıllarda örgütlerdeki güven ve güvensizlik çalışmalarına yönelik çarpıcı bir şekilde akademik ilgi 
olmuştur (Kramer, 1999). Öyle ki, hızla büyüyen literatürün bu durumunun değerlendirmesine yönelik Kramer (1999) tarafından bir çalışma kaleme alınmıştır.

Bunun ötesinde, yenilikçi örgütlerde kültürün rolünü tanımlamak için uygulama alanı bulan kontrol teorisi (Büschgens vd., 2013), örgütsel kontrolün, bireyleri örgütsel amaçlarla tutarlı bir şekilde hareket etmeye motive etmeyi amaçlayan yönetim faaliyetine yönelik bir teori olarak karşımıza çıkmaktadır.

\section{SONUÇ}

Bu çalışmanın amacı, kuramsal çerçevede örgütsel bir kültür olarak pazarlama kavramına açıklık getirmektir. Bu temelde çalışmaya örgütlerde bir kültür olarak pazar yöneliminin felsefi temellerinden başlanmış ve konu ile ilgili yazın çalışmaları incelenmiştir. İlgili literatüre yönelik yapılmış olan incelemenin özet sonucunu aşağıda olduğu gibi göstermek mümkündür.

1950’li Yıllar: Pazar yönelimi, pazarlama kavramının tanıtıldığı 1950’lerin başlarından bu yana pazarlama düşüncesinin temelini temsil etmektedir.

1960’lı Yıllar: Pazarlama yöneliminin büyüyen pazarlarda kârlı ilerlemenin temel bir unsuru olarak kabul edildiği 1960'lar, pazarlamanın etkisinin en büyük ve nüfuzunun baskın olduğu dönemdir. Yeni rekabet güçlükleriyle karşılaşılmasına karşın 1960'ların sonlarında ise pazar biçimi olarak örgütler popülerlik kazanmıştır.

1970'li Yıllar: 1970’li yılların öncesinden 1980'li yılların başına kadar akademisyenler, örgütsel kültür kavramına ciddi bir ilgi göstermeye başlamışlardır. Böylece örgütsel çalışmaların patlak verdiği 1980'lerin başından beri, literatür birçok ilginç aşamada gelişim göstermiştir.

1980’li Yıllar: 1980’lerde akademisyen ve uygulamacıların ilgileri pazar yönelimi kavramına kaymıştır. 1980’lerde pazar yönelimi konusuna yönelik ilk çalışmaların yapıldığı görülmektedir (Bakınız, Deshpande ve Webster (1989).

1990’lı Yıllar: 1990'larda kültür tanımları ve pazarlama kavramları birbirleri ile entegre edilmiştir. Böylece, pazarlama kavramı, bir kültür olarak tanıtılmıştır. Örgütsel bir kültür olarak pazar yönelimli bir kültür, müşteri yönelimi, rakiplere odaklanma ve işlevler arasındaki koordinasyon şeklinde üç ana davranıştan oluşmaktadır (Bakınız, Narver ve Slater, 1990). Bunun yanı sıra 1990’lı yıllarda pazar güdümlü ve müşteri yönlü olarak pazarlama olguları, birer kaynak olarak kaynak temelli yaklaşım çerçevesinde ele alınmıştır (Bakınız, Day, 1994). Yine aynı şekilde kaynak temelli yaklaşım ile ilişkili rekabetçi avantaj model teorisi ortaya atılmıştır (Bakınız, Hunt ve Morgan, 1995). Böylece bu rekabetçi model teorisi çerçevesinde firma 
performansı, pazar yönelimi ve yenilikler etkisinde ilk kez incelenmiştir. Sonuç olarak, pazar yönelimi tanımı daha da gelişim göstermiştir. Zira, bu yıllarda pazar yönelimi ve iş performansıyla bağlantılı olarak müşteri perspektifinin, uzun vadeli perspektifin ve kapsamlı perspektifin ilk defa tanımı yapılmıştır (Bakınız, Narver ve Slater, 1990). Aynı zamanda 1990’lı yıllarda müşteri yönelimi bakış açısının (Bakınız, Deshpande vd., 1993) ve kültürel temelli davranışsal bakış açısının (Bakınız, Narver ve Slater, 1990) pazar yönelimi karar verme bakış açılarından olduğu görülmektedir. Nihayet, 1998 yılına gelindiğinde pazar yönelimin, yenilikçilik yapıları ve örgütsel öğrenme bağlamında ele alınması gerektiği ileri sürülmüştür (Bakınız, Hurley ve Hult, 1998). Ancak, bu konuya yönelik çalışmalar, 2000'li yıllar itibari ile kaleme alınmıştır.

Özetle, 1991 ve 2001 arasındaki yıllarda hem pazarlama teorisyenleri hem de kaynak temelli yaklaşım taraftarları, “Örgütsel hayatta kalmanın kalbindeki rekabet üstünlüğüne neden olan nedir ve nasıl sürdürülebilir?” şeklinde en temel sorunla doğrudan ilgilenmişlerdir. Öyle ki, 1990’lı yıllarda iktisat bilgisine dayanan kaynak temelli yaklaşımın savunuculuğu yapılmıştır. $\mathrm{Bu}$ savunuculuğun ardından, örgütsel strateji perspektifinden pazar yönelimi derecesi ile iş süreçleri düzeyinde örgütsel süreçler, bireysel tutumlar ve uzun dönemli finansal performans arasındaki ilişkiler çalışma konusu olmuştur. Keza, 1990'ların ilk yarısına kadar, pazar yöneliminin ölçülmesinde ve bu ölçümlerin firma performansıyla ilişkilendirilmesinde kayda değer bir ilerleme vardır. 1990’lı yılların ilk yarısının sonlarına gelindiğinde, bağlılık ve güven teorisi, özellikle, pazarlama ilişkilerinde ve ilişkisel pazarlama temelinde ilk kez tanıtılmıştır (Bakınız, Morgan ve Hunt, 1994). Böylece bu yıllarda, ilişkisel pazarlamanın ortaya çıkış nedenleri ilgili çalışmalarda tartışma konusu olmuştur. Buna karşı1ık, 1990’11 yılların ortasında, pazar rekabeti ve endüstri çatışmasının algılanan yoğunluğu, ürün yaşam döngüsü ve pazar yönelimi arasındaki bağıntı temelinde açıklanmıştır (Bakınız, Atuahene-Gima, 1995). Aynı zamanda 1990'lı yılların ortasında, daha önce belirtildiği üzere rekabet avantajını incelemek için firmanın rekabet avantajını ve yetkinliklerini temel alan, rekabetçi ya da kaynak avantajlı teori önerilmiştir (Bakınız, Hunt ve Morgan, 1995). Böylece, strateji oluşturmada hem müşteriler hem de rakipler hakkında bilgi kullanmanın önemine yönelik bir kaynak olarak pazar yönelimi kavramına vurgu yapılmıştır. Nihayetinde, 1990’lı yılların sonlarına gelindiğinde belirli bir çerçevede, pazarlama olguları, sırayla paydaş değeri oluşturmadaki üç temel iş sürecine; ürün geliştirme yönetimine, tedarik zinciri yönetimine ve müşteri ilişkileri yönetimine gömülü olarak yeniden tanımlanmıştır (Bakınız, Srivastava vd., 1999). Sonuç olarak, 1990’lı yılların başından 
sonlarına kadar örgüt kültürünün ve ilgili davranışların performans üzerindeki etkisini inceleyen giderek büyüyen bir literatür gövdesi gelişim göstermiştir.

2000'li Yıllar: Geçen yılların ardından özellikle 1990’lı yıllardan günümüze pazarlama teorisi ve uygulamalarında pazar yönelimden ilişki yönelimine doğru bir paradigma kayması olmuştur. Böylece ilişkisel pazarlamaya olan gereksinimin iyice körüklenmesi ile bu çerçevede bağlılık ve güven teorisi bir model olarak ilk kez tanıtılmıştır. Diğer taraftan örgütler arası ilişskinin satın alma işlem veya davranışlardan kaynaklı olduğu görülmektedir. Kısaca, 2000’li yılların daha başlarında yani 2001 yılında, kaynak temelli yaklaşımın, pazarlama ile olan ilişkisini ele almak için pazar temelli kaynaklarına yönelik analizler yapılmıştır ve pazarlamaya özgü kaynaklar açıklanmıştır (Bakınız, Srivastava vd., 2001). Bununla beraber 2000'li yılların ortasında 2005 yılında, müşteri yönelimli kültür, müşteri yönelimli davranışlar ve örgütsel performans arasındaki ilişki üzerinde durulmuştur (Bakınız, Gainer ve Padanyi, 2005). Bununla birlikte, 2005 yılının ardındaki yıllarda yapılıış olan çalışmalarda pazar yönelimi, yenilikçi kültür, marka performans1, firma performansı veya örgütsel performans, örgütsel öğrenme, örgütsel yenilikler, destekleyici örgüt kültürü, yenilikçi örgüt kültürü, pazar yenilikçiliği, pazarlama yeniliği, bilgi yönetimi ve ürün yaşam döngüsü temelinde açıklanmıştır (Bakınız, O’Cass ve Viet Ngo, 2007; Wong ve Ellis, 2007; Danişman ve Erkocaoğlan, 2008; Farley vd., 2008; Bulut vd., 2009; Knowles ve Ambler, 2009; Eskiler vd., 2011; Usta, 2011; Eris ve Ozmen, 2012; Büschgens vd., 2013; Keskin vd., 2016; Raj ve Srivastava, 2016; Jogaratnam, 2017). Aynı zamanda, kontrol teorisi yenilikçi örgütlerde kültürün rolünü tanımlamak için uygulama alanı bulmuştur (Bakınız, Büschgens vd., 2013).

1950 Yıllından Günümüze Yönelik Bir Özet: Bir örgütsel kültür olarak pazarlama kavramına açılık getirmek için pazar yönelimi kavramı üzerinde durmak gerekmektedir. Çünkü, pazar yönelimi olgusunun, kaynak temelli yaklaşım, ürün yaşam döngüsü, rekabetçi avantaj, örgüt performansı ve yenilikçilik olarak bir dizi örgütsel kültür boyutu ve bu örgütsel kültür boyutların alt bileşenleri ile bir şekilde anlamlı bir ilişki içinde olduğu görülmektedir. 


\section{KAYNAKÇA}

Achrol, R. S. (1991), “Evolution of The Marketing Organization: New Forms for Turbulent Environments”, The Journal of Marketing, 55(4), 77-93.

Akman, G. (2003), "Bilişim Sektöründe Pazar Odaklılık, Yenilik Stratejileri ve Yenilik Kabiliyeti Arasındaki İlişkiler ve Bunların Şirket Performansı Üzerindeki Etkileri”, Gebze Yüksek Teknoloji Enstitüsü, Sosyal Bilimler Enstitüsü, (Yayınlanmamış Doktora Tezi).

Anderson, P. F. (1982), “Marketing, Strategic Planning and the Theory of The Firm”, The Journal of Marketing, 46(2), 15-26.

Atilla, E. A. (2000), "Hastanelerde Pazar Odaklılı̆̆ın İşletme Performansına Etkisi”, Gazi Üniversitesi Sosyal Bilimler Enstitüsü, Ankara, (Yayınlanmamış Doktora Tezi).

Atuahene-Gima, K. (1995), “An Exploratory Analysis of the Impact of Market Orientation on New Product Performance”, Journal of Product Innovation Management, 12(4), 275-293.

Barney, J. (1991), “Firm Resources and Sustained Competitive Advantage”, Journal of Management, 17(1), 99-120.

Barney, J., Wright, M. ve Ketchen Jr, D. J. (2001), “The Resource-Based View of the Firm: Ten Years After 1991”, Journal of Management, 27(6), 625-641.

Bulut, Ç., Yılmaz, C. ve Alpkan, L. (2009), “Pazar Oryantasyonu Boyutlarının Firma Performansına Etkileri”, Ege Academic Review, 9(2), 513-538.

Büschgens, T., Bausch, A. ve Balkin, D. B. (2013), “Organizational Culture and Innovation: A Meta-Analytic Review”, Journal of product innovation management, 30(4), 763-781.

Camerer, C. ve Vepsalainen, A. (1988), “The Economic Efficiency of Corporate Culture”, Strategic Management Journal, 9(S1), 115-126.

Cameron, K. S. ve Quinn, R. E. (2006), Diagnosing and Changing Organizational Culture: Based on the Competing Values Framework. John Wiley \& Sons.

Can, E. (1997), Pazara dönüklük; Firma Performansı ve Kârlılık İlişkisi. Marmara Üniversitesi, Sosyal Bilimler Enstitüsü, İstanbul, (Yayınlanmamış Doktora Tezi).

Christensen, L. T. (1995), "Buffering Organizational Identity in the Marketing Culture”, Organization Studies, 16(4), 651-672.

Collis, D. J. (1994), “Research Note: How Valuable Are Organizational Capabilities?”, Strategic Management Journal, 15(S1), 143-152.

Cyert, R. M. ve March, J. G. (1963), A Behavioral Theory of the Firm, Englewood Cliffs, NJ: Prentice-Hall. 
Danişman, A. ve Erkocaoğlan, E. (2008), “Pazar Yönelimi-Firma Performansı İlişkisi: İMKB’ye Kote Firmalar Üzerinde Bir Araştırma”, Selçuk Üniversitesi Sosyal Bilimler Enstitüsü Dergisi, (19), 197-212.

Day, G. S. (1994), “The Capabilities of Market-Driven Organizations”, The Journal of Marketing, 58(4), 37-52.

Day, G. S. (1981), “Strategic Market Analysis and Definition: An Integrated Approach”, Strategic Management Journal, 2(3), 281-299.

Day, G. S. ve Wensley, R. (1983), “Marketing Theory with A Strategic Orientation”, Journal of marketing, 47(4), 79-89.

Dean, J. (1950), “Pricing Policies for New Products”, Harvard Business Review, 28, 45-53.

Denison, D. R. (1996), "What İs the Difference Between Organizational Culture and Organizational Climate? A Native's Point of View on A Decade of Paradigm Wars”, Academy of Management Review, 21(3), 619-654.

Denison, D. R. ve Mishra, A. K. (1995), “Toward A Theory of Organizational Culture and Effectiveness”, Organization Science, 6(2), 204-223.

Deshpandé, R. ve Farley, J. U. (1999), “Corporate Culture and Market Orientation: Comparing Indian and Japanese Firms”, Journal of International Marketing, 7(4), 111-127.

Deshpandé, R. ve Farley, J. U. (2004), “Organizational culture, Market Orientation, Innovativeness, and Firm Performance: An International Research Odyssey”, International Journal of Research in Marketing, 21(1), 3-22.

Deshpandé, R., Farley, J. U. ve Webster Jr, F. E. (1993), “Corporate Culture, Customer Orientation, and innovativeness in Japanese firms: a quadrad analysis”, The journal of Marketing, 57(1), 23-37.

Deshpandé, R. ve Webster, Jr, F. E. (1989), “Organizational Culture and Marketing: Defining the Research Agenda”, The Journal of Marketing, 53(1), 3-15.

Eris, E. D. ve Ozmen, O. N. T. (2012), “The Effect of Market Orientation, Learning Orientation and Innovativeness on Firm Performance: A Research from Turkish Logistics Sector”, International Journal of Economic Sciences \& Applied Research, 5(1), 77-108.

Erdoğan, B. Z., Tiltay, M. A. ve Kimzan, H. S. (2011), “Pazarlama Teorisi’nin Felsefi Temelleri: Değişim mi, İlişki mi?”, Tüketici ve Tüketim Araştırmaları Dergisi, 3(1), 1-28.

Eskiler, E., Özmen, M. ve Uzkurt, C. (2011). Bilgi Yönetimi Pazar Odaklılık ve Pazarlama Yeniliği İlişskisi: Mobilya Sektöründe Bir Araştırma. Eskişehir Osmangazi Üniversitesi İktisadi ve İdari Bilimler Fakültesi Dergisi, 6(1), 3169.

Farley, J. U., Hoenig, S. ve Ismail, Z. (2008), “Organizational Culture, İnnovativeness, Market Orientation and Firm Performance in South Africa: An Interdisciplinary Perspective”, Journal of African Business, 9(1), 59-76. 
Gainer, B. ve Padanyi, P. (2005), “The Relationship Between Market-Oriented Activities and Market-Oriented Culture: Implications for the Development of Market Orientation in Nonprofit Service Organizations”, Journal of Business Research, 58(6), 854-862.

Gatignon, H. ve Xuereb, J. M. (1997), “Strategic Orientation of the Firm and New Product Performance”, Journal of marketing research, 77-90.

Glazer, R. (1991), “Marketing in An Information-Intensive Environment: Strategic Implications of Knowledge As An Asset”, The Journal of Marketing, 55(4), 1-19.

Harris, L. C. ve Ogbonna, E. (2001), "Strategic Human Resource Management, Market Orientation, and Organizational Performance”, Journal of Business Research, 51(2), 157-166.

Hatiboğlu-Yalman, N. (2003), "Moderators of the Relationship Between Market Orientation and Business Performance: Findings from Turkey”, Boğaziçi University, Institute of Social Sciences, (Yayınlanmamış Doktora Tezi).

Hunt, S. D. (2000), A General Theory of Competition. Thousand Oaks, CA: Sage Publications.

Hunt, S. D. ve Morgan, R. M. (1995), “The Comparative Advantage Theory of Competition”, The Journal of Marketing, 59(2), 1-15.

Homburg, C. ve Pflesser, C. (2000), “A multiple-layer model of market-oriented organizational culture: Measurement issues and performance outcomes”, Journal of marketing research, 37(4), 449-462.

Hurley, R. F. ve Hult, G. T. M. (1998), “Innovation, Market Orientation, and Organizational Learning: An Integration and Empirical Examination”, Journal of Marketing, 62(3), 42-54.

Jaworski, B. J. ve Kohli, A. K. (1993), “Market Orientation: Antecedents and Consequences”, The Journal of Marketing, 57(3), 53-70.

Jogaratnam, G. (2017), “How Organizational Culture Influences Market Orientation and Business Performance in the Restaurant Industry”, Journal of Hospitality and Tourism Management, 31, 211-219.

Joseph, O. O. ve Francis, K. (2015), “The Influence of Organizational Culture and Market Orientation on Performance of Microfinance İnstitutions in Kenya”, International Journal of Business and Management, 10 (8), 204.

Keskin, H., Zehir, S. ve Hayat, A. Y. A. R. (2016), “Pazar yönelimi ve Firma Performansı İlişkisi: Farklılaştırma Stratejisinin Aracı Rolü”, Doğuş Üniversitesi Dergisi, 17(1), 111-127.

Knowles, J. ve Ambler, T. (2009), “Orientation and Marketing Metrics”, The SAGE Handbook of Marketing Theory, 379. 
Kohli, A. K. ve Jaworski, B. J. (1990), "Market Orientation: The Construct, Research Propositions, and Managerial Implications”, Journal of marketing, 54(2), 1-18.

Kohli, A. K., Jaworski, B. J. ve Kumar, A. (1993), “MARKOR: A Measure of Market Orientation”, Journal of Marketing Research, 30(4), 467-477.

Kramer, R. M. (1999), “Trust and Distrust in Organizations: Emerging Perspectives, Enduring Questions”, Annual Review of Psychology, 50(1), 569-598.

Leisen, B., Lilly, B. ve Winsor, R. D. (2002), “The Effects of Organizational Culture and Market Orientation on the Effectiveness of Strategic Marketing Alliances”, Journal of Services Marketing, 16(3), 201-222.

Lippman, S. A. ve Rumelt, R. P. (1982), “Uncertain Imitability: An Analysis of Interfirm Differences in Efficiency Under Competition”, The Bell Journal of Economics, 13(2), 418-438.

Lockett, A. ve Thompson, S. (2001), “The Resource-Based View and Economics”, Journal of Management, 27(6), 723-754.

Lusch, R. F., \& Laczniak, G. R. (1987), “The Evolving Marketing Concept, Competitive Intensity and Organizational Performance”, Journal of the Academy of Marketing Science, 15(3), 1-11.

March, J. G. ve Simon, H. A. (1958), Organizations. New York: John Wiley \& Sons.

Morgan, R. M. ve Hunt, S. D. (1994), “The Commitment-Trust Theory of Relationship Marketing”, The Journal of Marketing, 58(3), 20-38.

Narver, J. C. ve Slater, S. F. (1990), “The Effect of A Market Orientation On Business Profitability”, The Journal of Marketing, 54(4), 20-35.

O'Cass, A. ve Viet Ngo, L. (2007), “Market Orientation Versus İnnovative Culture: Two Routes to Superior brand Performance”, European Journal of Marketing, 41(7/8), 868-887.

Penrose, E. T. (1959), The Theory of Growth of the Firm. Blackwell: Oxford.

Pfeffer, J. ve Salancik, G. R. (1978), The External Control of Organizations, New York: Harper and Row.

Raj, R., ve Srivastava, K. B. (2016), "Mediating Role of Organizational Learning on the Relationship Between Market Orientation and Innovativeness”, The Learning Organization, 23(5), 370-384.

Richardson, G. B. (1972), “The Organisation of Industry”, The Economic Journal, 82(327), 883-896.

Ruekert, R. W. (1992), “Developing A Market Orientation: An Organizational Strategy Perspective”, International Journal of Research in Marketing, 9(3), 225-245. 
Sheth, J. N. ve Sharma, A. (1997), “Supplier Relationships: Emerging Issues and Challenges”, Industrial Marketing Management, 26(2), 91-100.

Simon, H. A. (1955), “A Behavioral Model of Rational Choice”, The Quarterly Journal of Economics, 69(1), 99118.

Simon, H. A. (1959), “Theories of Decision-Making in Economics and Behavioral Science”, The American Economic Review, 49(3), 253-283.

Simon, H. A. (1964), “On the Concept of Organizational Goal”, Administrative Science Quarterly, 9(1), 1-22.

Srivastava, R. K., Fahey, L. ve Christensen, H. K. (2001), “The Resource-Based View and Marketing: The Role of Market-Based Assets in Gaining Competitive Advantage”, Journal of Management, 27(6), 777-802.

Srivastava, R. K., Shervani, T. A. ve Fahey, L. (1999), “Marketing, Business Processes, and Shareholder Value: An Organizationally Embedded View of Marketing Activities and the Discipline of Marketing”, The Journal of Marketing, 63(4_suppl1), 168-179.

Teece, D. J. (1980), "Economies of Scope and the Scope of the Enterprise”, Journal of Economic Behavior and Organization, 1(3), 223-247.

Tek, Ö. B. (1997), Pazarlama İlkeleri: Türkiye Uygulamaları: Global Yönetimsel Yaklaşım. Cem Ofset.

Turner, G. B. ve Spencer, B. (1997), “Understanding the Marketing Concept As Organizational Culture”, European Journal of marketing, 31(2), 110-121.

Usta, R. (2011),” Pazar Yöneliminin Firma Performansına Etkisini Güçlendiren Stratejik Yönelimler: Literatüre Dayalı Bütünsel Bir Model Önerisi”, Anadolu University Journal of Socıal Sciences, 11 (3), 65-84.

Uzkurt, C. (2003), “Pazar Yönlülük ve Firma Performansına Etkisi: Türkiye’nin Büyük Sanayi İşletmeleri Üzerine Bir Araştırma”, Pazarlama İletişimi Dergisi, 5(5).

Webster Jr, F. E. (1992), “The Changing Role of Marketing in the Corporation”, The Journal of Marketing, 56(4), $1-17$.

Wong, H. K. ve Ellis, P. D. (2007), “Is Market Orientation Affected by the Product Life Cycle?”, Journal of World Business, 42(2), 145-156.

Yenilmez, B. (2000a), "Pazar Yönelimi (Market Orientation) Kavramı: Türkiye’de Sigorta ve Bankacılık Sektörlerinde Pazar Yönelimi Ölçeklerini Karşılaştıran Bir Araştırma”, Akdeniz Üniversitesi, Sosyal Bilimler Enstitüsü, Antalya, (Yayınlanmamış Yüksek Lisans Tezi).

Yenilmez, B. (2000b), "Pazar Yöneliminin (Market Orientation) İşletme Performansı Üzerindeki Etkilerini İrdeleyen Bir Araştırma”, 5. Ulusal Pazarlama Kongresi Bildiriler Kitabı, 16-18.

Zhou, K. Z., Yim, C. K. ve Tse, D. K. (2005), “The Effects of Strategic Orientations on Technology-and MarketBased Breakthrough İnnovations”, Journal of Marketing, 69(2), 42-60. 